
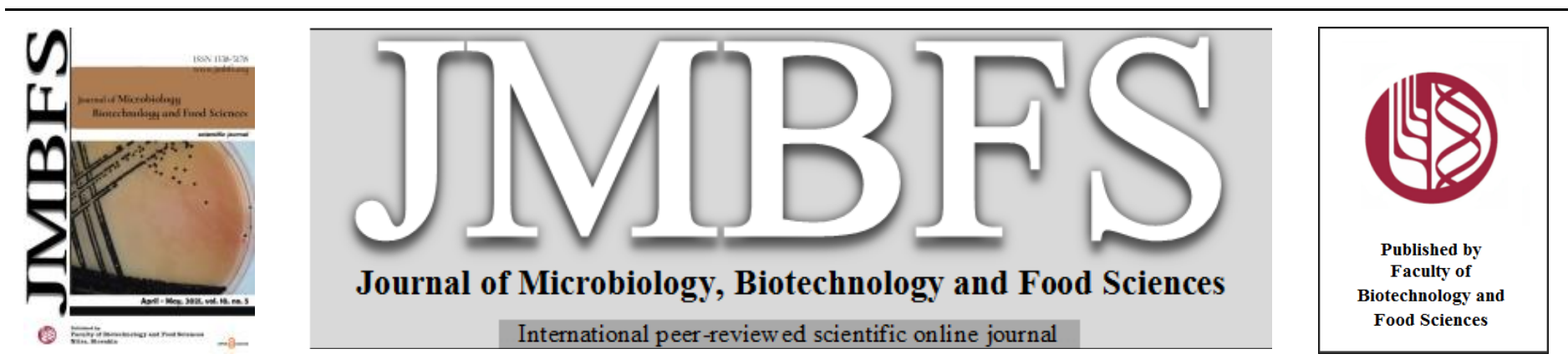

\title{
HEALTH PROMOTING BREAD; COMPRISING NATURAL-MIRACLE ANTHOCYANINS
}

\author{
Suleyman Asir ${ }^{1}$, Hurmus Refiker*² \\ Address(es): Assist. Prof. Dr. Hurmus Refiker \\ ${ }^{1}$ Near East University, Faculty of Engineering, Department of Materials Science and Nanotechnology Engineering, Near East Boulevard, ZIP: 99138 Nicosia North \\ Cyprus Mersin 10 - Turkey. \\ ${ }^{2}$ Near East University, Faculty of Pharmacy, Department of Analytical Chemistry, Near East Boulevard, ZIP: 99138 Nicosia North Cyprus Mersin 10 - Turkey.
}

*Corresponding author: hurmus.refiker@neu.edu.tr

https://doi.org/10.15414/jmbfs.3354

\section{ARTICLE INFO}

Received 29. 6. 2020

Revised 5. 12. 2020

Accepted 7. 12. 2020

Published 1. 4. 2021

\section{Regular article}

OPEN $\partial_{\text {ACCESS }}$

\begin{abstract}
The phenolic aqueous extract from red cabbage was incorporated into bread and stability and contribution of anthocyanins comprising bread samples have been investigated. Assessment of total monomeric anthocyanin in sample bread stored both at room temperature and at $4{ }^{\circ} \mathrm{C}$, on different days; first, third, sixth and $32^{\text {nd }}$ day of storage, was carried out. The total phenolic content and total antioxidant capacity of sample bread were measured by the Folin-Ciocalteu (FC) procedure and the oxygen radical absorbance capacity (ORAC) method, respectively. Total phenolic contents were estimated as $91.88 \pm 2.42 \mathrm{mg} \mathrm{GAE} / 100 \mathrm{~g}$ and ORAC value was calculates as $1387 \pm$ $153 \mu \mathrm{mol} \mathrm{TE} / 100 \mathrm{~g}$ (DW;Dry weight). No colonies of mold were monitored in sample bread when kept at $4{ }^{\circ} \mathrm{C}$ for almost three weeks retaining its antioxidant properties. These innovative and health promoting bread samples might be inspiring for public and the molecular gastronomy and food science researches as well as in the near future.
\end{abstract}

Keywords: Anthocyanins, bread, health benefits, red cabbage, radicals

\section{INTRODUCTION}

Currently, bread consumption is higher than 9 billon $\mathrm{kg}$ annually. Therefore, bread is one of the most accepted and consumed food products throughout the world. It contains macronutrients (carbohydrates, protein and fat) and micronutrients (minerals and vitamins) which are all necessary for human health (Durović S and co-workers 2020).

More than 20 years, there is a growing interest in health benefits of plant based polyphenols mainly anthocyanins which are a subgroup of flavonoids responsible for the blue, purple, and red color of many fruits, flowers, and leaves (Jim F. 2014). Anthocyanins are important due to their antioxidant activity which is effective in the prevention and control of oxidative stress-related diseases. Oxidative stress is caused when there is an imbalance between reactive oxygen species production and antioxidant defenses. Free radical mechanisms could be realted to age-related and chronic diseases such as diabetes, cancer, cardiovascular and neurodegenerative diseases (Dranca F. and Oroian M. 2017).

Red cabbage (Brassica oleracea L.) dye is commonly used on food industry as natural food colorants. Major pigments responsible for a wide spectrum of color tones changing from orange through red to purple and blue are anthocyanins. These changes in color are dependent on molecular structure and $\mathrm{pH}$ value (Kalt W. 2005).

In terms of chemistry; anthocyanins, water soluble pigments, occur as glycosides and contain one of the several aglycone (anthocyanidins) cores (WalkowiakTomczak D. and Czapski J. 2007). The aglycone core of red cabbage is found to be cyanidine which is attached to carbohydrate moiety at both 3 and 5 position (Chigurupati N. et al 2002.) In acidic solution, the aglycone core can exist as a positively charged oxonium ion, called red flavylium cation; the exact color of solution is $\mathrm{pH}$ dependent. Anthocyanin glycoside residues are mostly acylated with phenolic acids. It was recorded that anthocyanin stability is increased with glycosidation and acylation of glycoside residues (Walkowiak-Tomczak D. and Czapski J. 2007).

Charron and coworkers stated that anthocyanins in the aglycone, glucosidic acylated forms are absorbed by humans (Charron C. and co-workers 2007). It was also mentioned that anthocyanins consumption even at high doses does not exhibit any toxic, teratogenic and mutagenic properties (Clifford M. 2000). A. Baiano and co-workers (2015) studied the production of functional bread by replacing water with aqueous extracts of solid wastes from celery, chicory, cabbage, fennel, olive leaves, and grape marc. They recorded that the highest phenolic contents and antioxidant activity were achieved with breads prepared by the vegetable waste extracts derived from grape marc and olive leaves. X. Su and workers (2015) investigated anthocyanin-rich black rice powder incorporated into bread. Two specific anthocyanins,cyanidin-3-glucoside and cyanidin-3-rutinoside, during baking were monitored where cyanidin-3rutinoside was recorded to be more thermally stable.

The objective of our study was to prepare functional bread made up of natural extract rich in anthocyanins so that when consumed it would potentially promote health maintenance thought the life span.

\section{MATERIAL AND METHODS}

\section{Materials}

Wheat flour, yeast and red cabbage were purchased from local market in Guzelyurt, North Cyprus. All other chemicals and reagents used for the study were of analytical grade and were obtained from Sigma-Aldrich unless otherwise stated.

\section{Preparation of Red Cabbage Extracts}

Samples of approximately $550 \mathrm{~g}$ of red cabbage leaves were weighed, chopped and extracted with $900 \mathrm{~mL}$ of water at high temperature $\left(\leq 100{ }^{\circ} \mathrm{C}\right)$ under optimized conditions. After extraction, chopped leaves were filtered and extracts were put in clean brown bottles prior to addition to bread dough samples. Daily fresh extracts were prepared and used in bread preparation throught the study.

\section{Preparation of Bread Samples}

Bread samples were prepared by straight dough method mentioned elsewhere with slight changes (Amendola J.and Rees N. 2002). All the ingredients including extract aliquots were initially weighed added to white wheat flour and kneaded homogeneously. Finally, dough was molded into round shape bread samples. For the preparation of control group samples, same materials except for the extract aliquots and methods have been applied. They were all kept for bulk fermentation under a cover for 30 minutes at $30^{\circ} \mathrm{C}$. The baking was carried out in a preheated baking oven at $190{ }^{\circ} \mathrm{C}$ for 35 minutes. Baked bread samples were then depanned, left for cooling at ambient temperature and packed in ziploc bags prior to analyses. 


\section{Calculation of Protein, Ash and Moisture Contents}

Protein content was determined based on analysis of the total nitrogen content in bread samples by Dumas method (Mæhre HK. and co-workers 2018) Determination of ash and moisture contents of the bread sample was achieved applying the procedure mentioned in literature (AOAC 2000). For comparison, all the analyses have been applied for both anthocyanins comprising bread and control group (Figure 1).

\section{Determination of Total Monomeric Anthocyanin, color density, polymeric color, and \% contribution of tannin}

Identical sets of 5 grams of anthocyanin comprising bread samples were macerated in $20 \mathrm{~mL}$ of water/ethanol, $(1: 1 ; \mathrm{v} / \mathrm{v})$ where $\mathrm{pH}$ values were adjusted to be 0.6 and 3.5. Each sample solution was sonicated for 10 minutes in an ultrasonic bath (HF Frequency, 35kHz). Then the aliquots of extracts were centrifuged for 15 minutes at $3600 \mathrm{rpm}$. Sample solutions of control bread group were prepared similarly.

Total monomeric anthocyanin content was estimated by $\mathrm{pH}$ differential method mentioned elsewhere, with slight modifications (Cheng G. And Breen P. 1991) Briefly, absorbance values of each sample at $\mathrm{pH} 0.6$ and $\mathrm{pH} 3.5$ were recorded at the wavelengths of $531 \mathrm{~nm}$ (for the anthocyanin content determination) and 700 $\mathrm{nm}$ (for interference elimination from background) versus blank using a spectrometer (UV/VIS spectrometer T80+ PG Instruments). Absorbance (A) and concentration of total anthocyanins were calculated using the following equations 1 (Eqn.1) and 2 (Eqn.2), respectively where the total anthocyanin content was expressed as mg cyanindin-3-glucoside/kg FW (fresh weight).

$$
\mathrm{A}=\left[\left(\mathrm{A}_{531}-\mathrm{A}_{700}\right) \mathrm{pH}_{0.6}\right]-\left[\left(\mathrm{A}_{531}-\mathrm{A}_{700}\right) \mathrm{pH}_{3.5}\right]
$$

Anthocyanin concentration $(\mathrm{g} / \mathrm{L})=\left(\mathrm{A}^{*} \mathrm{MW}\right) /\left(\mathcal{C}^{*} \mathrm{l}\right) \quad$ Eqn.2

Where; $\mathrm{A}$ is the absorbance obtained from equation $1, \mathrm{MW}$ is the molecular weight of a reference pigment (cyanidin-3-glucoside) $(449.2 \mathrm{~g} / \mathrm{mol}), \varepsilon$ is the molar absorptivity $\left(26900 \mathrm{~L} / \mathrm{mol}^{*} \mathrm{~cm}\right)$ and 1 is the optical path length in centimeters (Lemos A. et al 2013).

Color density and polymeric color are determined by potassium meta bisulfite method. The color density is obtained by the addition of the absorbance of the control sample at $420 \mathrm{~nm}$ and at the anthocyanin $\lambda_{\max }$ where turbidity can be corrected for by subtracting any absorbance at $700 \mathrm{~nm}$. Once the sample is diluted, the sum is multiplied by the dilution factor (DF). Since the polymeric tannin pigments are resistant to bisulfite bleaching, polymeric color can be calculated by applying the same procedure as used in determining color density to the bisulfite treated sample. The percent contribution of tannin (nonmonomeric anthocyanin color) is the ratio of color density and polymeric color (Wroistad R. 1993). Experimental data used for calculations have been exhibited in Table 2.

\section{Calculation of Total Phenolic Content}

Estimation of total phenolic content was carried out by the Folin-Ciocalteu (FC) procedure (Kahkonen and co-workers 1999). The content of total phenolics was calculated on the basis of the standard curve using gallic acid as the standard. The results were expressed as milligrams of gallic acid equivalents per $100 \mathrm{~g}$ of sample (mg of GAE/100 g). All analyses were performed in duplicate.

\section{Calculation of Antioxidant Capacity}

The oxygen radical absorbance capacity (ORAC) assay has been used to measure the antioxidant activity according to procedure described elsewhere (Matthaus B. 2002). The ORAC values were determined using a microplate reader (FLUOStar Omega, BMG Labtech, Ortenberg, Germany). The ORAC value was calculated and expressed as micromole Trolox equivalents per 100 grams.

\section{RESULTS AND DISCUSSION}

\section{Protein, Ash and Moisture Contents}

All of the analysis results of protein, ash and moisture contents have been summarized in Table 1. Crude protein contents were calculated both for control bread and sample bread. No significant difference was obtained where it was 11.6 $\%$ and $11.7 \%$ for control and sample breads, respectively. Both values were in good agreement in literature (Morgounov A. et al 2020). Ash analysis showed only slight changes in results where it was calculated as $0.96 \%$ in sample bread and $0.78 \%$ in control bread. Moisture contents were calculated as $36.6 \%$ for sample bread and $36.9 \%$ for control bread which are all quite comparable in literature accepted values (Marpalle P. and co-workers 2014).

Table 1 Results of protein, ash and moisture contents, total antioxidant activity and total phenol content for sample bread and control bread.

\begin{tabular}{|c|c|c|c|c|c|}
\hline & $\begin{array}{l}\text { Moisture } \\
\%(\mathbf{m} / \mathbf{m})\end{array}$ & $\begin{array}{c}\text { Ash } \\
\%(\mathbf{m} / \mathbf{m})\end{array}$ & $\begin{array}{c}\text { Crude Protein } \\
\%(\mathbf{m} / \mathbf{m})\end{array}$ & $\begin{array}{l}\text { Total antioxidant activity } \\
\quad\left(\mu \mathrm{mol} \text { TE } 100^{-1} \mathrm{~g}\right)\end{array}$ & $\begin{array}{c}\text { Total phenol } \\
\text { content mg GAE } \\
100^{-1} \mathrm{~g}\end{array}$ \\
\hline Sample bread & 36.6 & 0.96 & 11.7 & $1387 \pm 153$ & $91.88 \pm 2.42$ \\
\hline Control bread & 36.9 & 0.78 & 11.6 & $437 \pm 117$ & $36.75 \pm 1.75$ \\
\hline
\end{tabular}

\section{Total Monomeric Anthocyanin and Extended Shelf Lif}

Assessment of total monomeric anthocyanin in sample bread was carried out when stored at room temperature and at $4{ }^{\circ} \mathrm{C}$, on different days; first, third, sixth and $32^{\text {nd }}$ day of storage and presented in Table 2. During those days, identical sample breads were prepared, one set was kept at room temperature; others were stored in refrigerator at $4{ }^{\circ} \mathrm{C}$. Control bread group were also prepared for monitoring. It was observed that storing sample breads at different temperatures did not affect amount of total monomeric anthocyanins severely. For instance, on the first day of storage, at room temperature total anthocyanin amount was $87 \mathrm{mg}$ $\mathrm{kg}^{-1} \mathrm{FW}$, and it was calculated as $85 \mathrm{mg} \mathrm{kg}^{-1} \mathrm{FW}$ at $4{ }^{\circ} \mathrm{C}$. Even on $32^{\text {nd }}$ of storage at $4{ }^{\circ} \mathrm{C}$, total monomeric anthocyanin was calculated as $86 \mathrm{mg} \mathrm{kg}^{-1} \mathrm{FW}$. Observation of both sample group and control group breads were recorded during the storage of 32 days. Apparently, anthocyanin-rich bread was more stable and was mold-free over longer periods of time when stored at $4{ }^{\circ} \mathrm{C}$. Control group bread developed molds towards the end of $3^{\text {rd }}$ day (Table 2).

In literature, M. Schaefer and co-workers reported that that the risk of fruit-rot in grape varieties infected with Botrytis cinerea decreased with increasing anthocyanin contents. Moreover, they emphasized anthocyanins, particularly one of the most common ones, cyanidin- 3-glucoside, have strong antifungal activity because only anthocyanins, were more concentrated in the strong antifunga extract of black blackberries than in the extract of red blackberries which still reduced fungal growth by $50 \%$ relative to the control (Schaefera M. et al 2008) In 2013, Yang Zhang and co-workers drew attention to the enrichment of anthocyanin in tomatoes could significantly extend shelf life. They showed that reduced susceptibility to Botrytis cinerea was dependent specifically on the accumulation of anthocyanins, resulting in high hydrophilic antioxidant capacity, which reduces the increase in reactive oxygen species (ROS) levels (Zhang Y. and co-workers 2013). Considering all, such a long shelf life such as 22 days at $4{ }^{\circ} \mathrm{C}$ without any mold development could be attributed to the presence of anthocyanins which reduced the susceptibility of bread to fungal pathogens. Even after 32 days, anthocyanin content could be conserved and calculated as $86 \mathrm{mg}$ $\mathrm{kg}^{-1} \mathrm{FW}$ which was highly close to first day result $\left(85 \mathrm{mg} \mathrm{kg}^{-1} \mathrm{FW}\right)$

The product acceptability and quality are primarily based on the pigmentation, or coloration of foods. It is known that, for fruits pigmented with anthocayanins, compounds are unstable when exposed to heat or long term storage. Therefore the highest quality raw materials containing large pigment concentration are crucial during product processing (Jackman R., et al 1987). In bread, higher anthocyanin stability is achieved with the lower amount of oxygen in the system. In bread preparation, yeast adjusts oxygen in producing carbon dioxide which enhances dough rising. This process decreased the anthocyanin oxidation (Amendola J. and Rees N. 2002). It was also noted that higher stabilities could be expressed with the presence of larger number of diacylated anthocyanins, which exhibit higher stabilities due to the pigments intramolecular and/or intermolecular copigmentation and self-association reactions. As the diacylation of anthocyainins increases their color stabilities increases (Ahmadiani N. and co-workers 2014). Considering all, the development of color density, polymeric color and $\%$ tanning contribution were monitored during up to 32 days of storage both at room temperature and $4{ }^{\circ} \mathrm{C}$. The correlation between anthocyanin degradation and these physiochemical parameters is presented in Table 2. It is crucial to emphasize that the $\mathrm{pH}$ differential method is a measure of the monomeric anthocyanin pigments and the results may not seem to be correlated with the color intensity of the juice or wine samples etc. as they are judged visually. The reason is polymeric anthocyanins and brown pigments arising from enzymic browning, maillard browning, and anthocyanin degradation also make a contribution to the color intensity. In products where browning and anthocyanin degradation took place, a better correlation with color intensity would be obtained but it would not be as accurate a measurement of anthocyanin content (Kahkonen M. et al 1999). Experimental data used in calculations of tota 
monomeric anthocyanins, color density and polymeric color for sample bread are exhibited in Table 3.

Table 2 Anthocyanin degradation and some physiochemical parameters of sample bread and control bread.

\begin{tabular}{|c|c|c|c|c|c|c|}
\hline & & $\begin{array}{c}\begin{array}{c}\text { Amount of } \\
\text { anthocyanins } \\
\left(\mathrm{mg} \mathrm{kg}^{-1}\right) \mathrm{FW}\end{array} \\
\end{array}$ & Observation & $\begin{array}{l}\text { Color } \\
\text { Density }\end{array}$ & $\begin{array}{l}\text { Polymeric } \\
\text { Color }\end{array}$ & $\begin{array}{c}\% \text { Contribution of } \\
\text { Tannin }\end{array}$ \\
\hline \multirow{12}{*}{$\begin{array}{l}\text { Sample } \\
\text { bread }\end{array}$} & 1. Day at RT* & 87 & normal & 1.9 & 1.03 & 54 \\
\hline & at $4{ }^{\circ} \mathrm{C}$ & 85 & normal & 1.9 & 0.67 & 35 \\
\hline & 3. Day at RT & 75 & normal & 1.9 & 0.67 & 35 \\
\hline & at $4{ }^{\circ} \mathrm{C}$ & 77 & normal & 1.8 & 0.59 & 33 \\
\hline & 6. Day at RT & 85 & mold & 1.9 & 0.29 & 15 \\
\hline & at $4{ }^{\circ} \mathrm{C}$ & 89 & normal & 1.6 & 0.51 & 32 \\
\hline & 11. Day at RT & $\mathrm{NC} * *$ & mold & $\mathrm{NC}$ & $\mathrm{NC}$ & $\mathrm{NC}$ \\
\hline & at $4{ }^{\circ} \mathrm{C}$ & $\mathrm{NC}$ & normal & $\mathrm{NC}$ & $\mathrm{NC}$ & $\mathrm{NC}$ \\
\hline & 22. Day at RT & $\mathrm{NC}$ & mold & $\mathrm{NC}$ & $\mathrm{NC}$ & $\mathrm{NC}$ \\
\hline & at $4{ }^{\circ} \mathrm{C}$ & $\mathrm{NC}$ & normal & $\mathrm{NC}$ & $\mathrm{NC}$ & $\mathrm{NC}$ \\
\hline & 32. Day at RT & $\mathrm{NC}$ & mold & $\mathrm{NC}$ & $\mathrm{NC}$ & $\mathrm{NC}$ \\
\hline & at $4{ }^{\circ} \mathrm{C}$ & 86 & mold & 1.9 & 1.03 & 55 \\
\hline \multirow{8}{*}{$\begin{array}{l}\text { Control } \\
\text { bread }\end{array}$} & 1. Day at RT* & none & normal & none & none & none \\
\hline & at $4{ }^{\circ} \mathrm{C}$ & none & normal & none & none & none \\
\hline & 3. Day at RT & none & mold & none & none & none \\
\hline & at $4{ }^{\circ} \mathrm{C}$ & none & normal & none & none & none \\
\hline & 6. Day at RT & none & mold & none & none & none \\
\hline & at $4{ }^{\circ} \mathrm{C}$ & none & normal & none & none & none \\
\hline & 11. Day at RT & none & mold & none & none & none \\
\hline & at $4{ }^{\circ} \mathrm{C}$ & none & mold & none & none & none \\
\hline
\end{tabular}

*RT: Room Temperature $\quad * *$ NC: Not Calculated.

Table 3 Experimental data used in calculations of total monomeric anthocyanins, color density and polymeric color for sample bread at room temperature (RT) and 4 ${ }^{\circ} \mathrm{C}$.

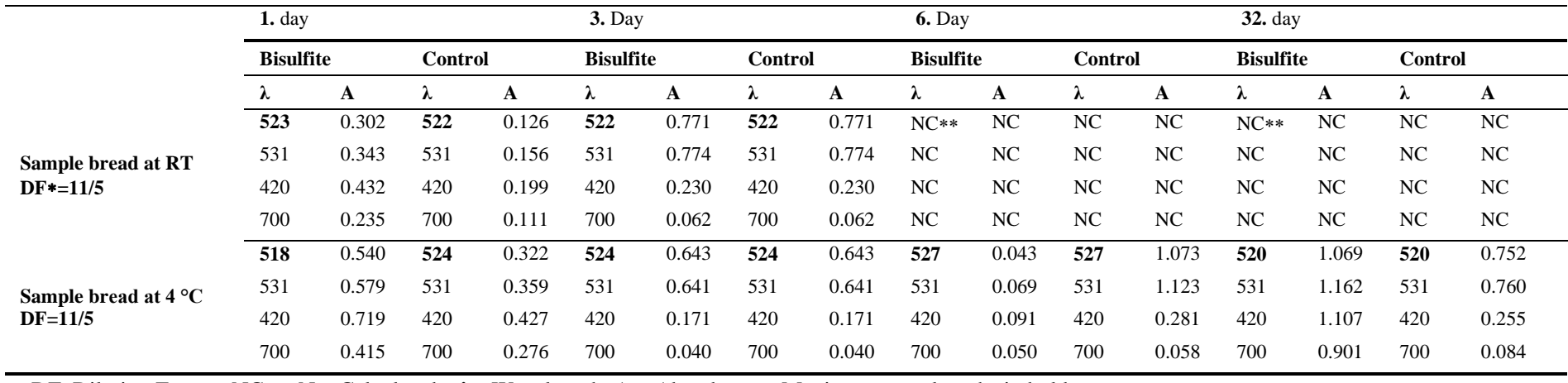

*DF: Dilution Factor, NC**: Not Calculated, $\lambda=$ Wavelength, $\mathrm{A}=$ Absorbance. Maximum wavelengths in bold

\section{Total Phenolic Content and Antioxidant Capacity}

Generally, thermal degradation of anthocyanins starts with the hydrolysis of sugar moieties, such as glucoside and rutinoside. Then deglycosylation of anthocyanins follows to form anthocyanidins which are further decomposed to chalcones. The phenolic acids and carboxyaldehydes are formed as a result of subsequent breakdown of chalcones. It was reported the degradation products of anthocyanins keep antioxidant properties therefore; thermal degradation may not affect severely their antioxidant capacity (Amendola J. and Rees N. 2002). The total phenolic content in sample bread was estimated as $91.88 \pm 2.42 \mathrm{mg}$ GAE/100 g. When similar analysis was applied to control group, it was only $36.75 \pm 1.75 \mathrm{mg} \mathrm{GAE} / 100 \mathrm{~g}$ (Table 1 ).

The phenolic compounds can catch free radicals. However its capacity is dependent on their structure, especially of the hydrogen atoms of the aromatic group that can be transferred to the free radicals and of the capacity of the aromatic compound to deal with the uncoupling of electrons as a result of the surrounding displacement of the electron- $\pi$ system. Anthocyanins are very effective donors of hydrogen to highly reactive free radicals; superoxide, singlet oxygen, peroxide, hydrogen peroxide and hydroxyl radical and reactive nitrogen species in a terminator reaction due to anthocyanin's positive charge, the number and arrangement of aromatic hydroxyl groups, the extent of structural conjugation and the presence of electron-donating and electron-withdrawing substituents in the ring structure, hence prevents further radical formation. This is the effect of protecting cells from oxidative damage which causes aging and various diseases, such as cancer, neurological and cardiovascular diseases, inflammation, diabetes and bacterial infections (Martín, J. and co-workers 2017). The ORAC method measures the capacity of antioxidants to donate hydrogen atom and the ORAC assay depends on the free radical damage to a fluorescent probe through the change in its fluorescence intensity. The change of fluorescence intensity is an index of the degree of free radical damage and in the presence of antioxidant, the inhibition of free radical damage by an antioxidant, is a measure of its antioxidant capacity against the free radical (Huang D. et al 2002).

In literature, anthocyanins have been reported to be cardioprotective, antidiabetic and to exhibit some anti-inflammatory and anticarcinogenic properties, as well as enhancing weight loss. Dietary choice is one of the important factors on the amount of anthocyanin consumption (Pojer E. and co-workes 2013). Therefore, it is worth recording the consumption of anthocyanins could exceed $200 \mathrm{mg} / \mathrm{day}$ and the daily intake of anthocyanins in humans has been estimated to range from several milligrams to hundreds of milligrams per person It is stated that a glass of red wine supplies around $115 \mathrm{mg}$ of polyphenols, contributing towards a total intake of phenolic compounds of $1171 \mathrm{mg} /$ person/day (Bueno M. et al 2012). In the current study, total antioxidant capacity of control bread was determined as $437 \pm 117 \mu \mathrm{mol} \mathrm{TE} / 100 \mathrm{~g}$ whereas in sample bread the capacity was $1387 \pm 153$ $\mu \mathrm{mol} \mathrm{TE} / 100 \mathrm{~g}$ which corresponds to $347 \mathrm{mg} / 100 \mathrm{~g}$.

\section{CONCLUSION}

In this study, functional bread made up of natural extract rich in anthocyanins has been prepared successfully. Experimental results have shown that sample bread is rich enough in anthocyanins and in terms of antioxidant property which could provide health benefits by preventing chronic diseases and cancer.

Besides promoting health, sample bread can be stored for longer periods without any artificial preservatives. Therefore enhanced stability, extended shelf life and affordability can increase food applications and overall consumption and maybe increase its positive role in human health. Decorative properties shown in Figure 1 of anthocyanin-rich bread can contribute to easy incorporation to specially children's dietary intake. These innovative and health promoting bread samples might be inspiring for public and the molecular gastronomy and food science researches as well as in the near future. It should be mentioned that as a further research, the identification of the major compounds that are generated during the baking of bread fortified with anthocyanins should be carried out. Besides, it may 
also be needed to conduct sensory tests to evaluate the bread fortified with anthocyanin-rich bread to prove its acceptability by consumers.

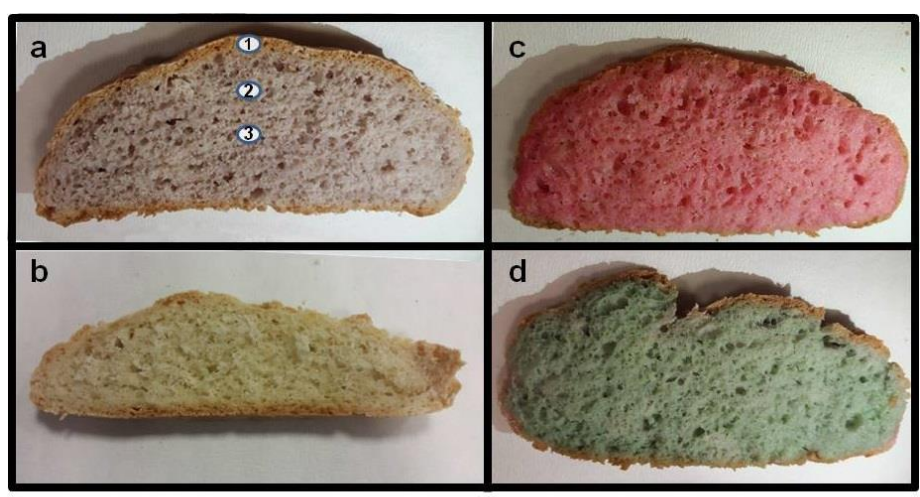

OSampling area: mixture of 1,2 and 3

Figure 1 Cross section of a; sample bread, b; control bread, c; sample bread at $\mathrm{pH} \leq 3$, d; sample bread at $\mathrm{pH} \geq 10$.

Acknowledgments: Authors are grateful to TÜBİTAK MAM and Nicosia Government Laboratory, TRNC for procurement of services.

CONFLICTS of INTEREST: The authors declare no conflict of interest.

\section{REFERENCES}

Durović S., Vujanović M., Radojković M., Filipović J., Filipović V., Gašić U., Tešić Z., Mašković P., Zeković Z. (2020): The functional food production: Application of stinging nettle leaves and its extracts in the baking of a bread. Food Chemistry, 312: 126091. https://doi.org/10.1016/j.foodchem.2019.126091

Jim F. (2014): Bioavailability of anthocyanins. Drug Metabolism Reviews, 4 508-520. https://doi.org/10.3109/03602532.2014.978080

Dranca F., Oroian M. (2017): Total Monomeric Anthocyanin, Total Phenolic Content and Antioxidant Activity of Extracts from Eggplant (Solanum Melongena L.) Peel Using Ultrasonic Treatments. Journal of Food Process Engineering, 40: e12312. https://doi.org/10.1111/jfpe.12312

Kalt W. (2005): Effects of Production and Processing Factors on Major Fruit and Vegetable Antioxidants. Journal of Food Science, 70: R11-R19. https://doi.org/10.1111/j.1365-2621.2005.tb09053.x

Walkowiak-Tomczak D., Czapski J. (2007): Colour changes of a preparation from red cabbage during storage in a model system. Food Chemistry, 104: 709714. https://doi.org/10.1016/j.foodchem.2006.10.079

Chigurupati N., Saiki L., Gayser C., Dash A. (2002): Evaluation of red cabbage dye as a potential natural color for pharmaceutical use. International Journal of Pharmaceutics, 241: 293-299. DOI: 10.1016/s0378-5173(02)00246-6

Charron C., Clevidence B., Britz S., Novotny J. (2007): Effect of dose size on bioavailability of acylated and nonacylated anthocyanins from red cabbage (Brassica oleracea L. Var. capitata), Journal of Agriculture and Food Chemistry, 55: 5354-5362. DOI: 10.1021/jf0710736

Clifford M. (2000): Anthocyanins - nature, occurrence and dietary burden, Journal of Science of Food and Agriculture, 80:1063-1072. https://doi.org/10.1002/(SICI)1097-0010(20000515)80:7<1063::AID-

JSFA605>3.0.CO;2-Q

Baiano A.,Viggiani I., Terracone C., Romaniello R., Del Nobile M. (2015) Physical and Sensory Properties of Bread Enriched with Phenolic Aqueous Extracts from Vegetable Wastes, Czech Journal of Food Science, 3: 247-253. https://doi.org/10.17221/528/2014-CJFS

Sui X., Yap P., Zhou W. (2015): Anthocyanins during baking: Their Degradation Kinetics and Impacts on Color and Antioxidant Capacity of Bread, Food and Bioprocess Technology, 8: 983-994. doi: 10.1007/s13197-015-2002-1

Amendola J., Rees N. (2002). Understanding baking: The art and science of baking. $3^{\text {rd }}$ Ed. John Wiley \& Sons, Inc: 151-168.

Mæhre HK, Dalheim L, Edvinsen GK, Elvevoll EO, Jensen IJ. (2018): Protein Determination-Method Matters, Foods, 7,5. DOI: 10.3390/foods7010005

AOAC (2000): Official Methods of Food Analysis, Association of Officia Analytical Chemists, Washington, DC, USA, $15^{\text {th }}$ edition.

Cheng G., Breen P. (1991): Activity of phenylalanine ammonia-lyase (PAL) and concentrations of anthocyanins and phenolics in developing strawberry fruit, Journal of the American Society for Horticultural Science, 116: 865-869. https://doi.org/10.21273/JASHS.116.5.865

Lemos A, Maryam M., Aliyu M., Kynoch G., Joseph L, Hungerford G. (2013): Effect of cooking on the levels of bioactive compounds in Purple Majesty Potato, InsideFood Symposium, 9-12 April 2013, Leuven, Belgium.

Wroistad R. (1993): Color and Pigment Analyses in Fruit Products, Agricultural Experiment Station Oregon State UniversityStation Bulletin 624 Reprinted May 1993.
Kahkonen, M. P., Hopia, A. I., Vuorela, H. J., Rauha, J. P., Pihlaja, K., Kujala, T. S., Heinonen, M. (1999): Antioxidant activity of plant extracts containing phenolic compounds, Journal of Agricultural and Food Chemistry, 47: 3954 3962. DOI: $10.1021 /$ jf 9901461

Matthaus B. (2002): Antioxidant activity of extracts obtained from residues of different oilseeds, Journal of Agricultural and Food Chemistry, 12: 3444-3452. DOI: $10.1021 /$ jf011440s

Morgounov A., Karaduman Y., Akin B., Aydogan S., Baenziger P., Bhatta M. Chudinov V., Dreisigacker S., Govindan V., Güler S., Guzman C., Nehe A., Poudel R., Rose D., Gordeeva E., Shamanin V., Subasi K.,Zelenskiy Y., Khlestkina E. (2020): Yield and quality in purple-grained wheat isogenic lines, Agronomy, 10: 86. https://doi.org/10.3390/agronomy10010086

Marpalle P., Sonawane S., Arya S. (2014): Effect of flaxseed flour addition on physicochemical and sensory properties of functional bread, LWT - Food Science and Technology, 58: 614-619. https://doi.org/10.1016/j.lwt.2014.04.003

Schaefera M., Rentzsch M., Breuer M. (2008): Anthocyanins reduce fungal growth in fruits, Natural Product Communications, 3: 1267-1272. https://doi.org/10.1177/1934578X0800300808

Zhang Y., Butelli E., De Stefano R., Schoonbeek H., Magusin A., Pagliarani C., Wellner N., Hill L., Orzaez D., Granell A., Jones J., Martin C. (2013), Anthocyanins Double the Shelf Life of Tomatoes by Delaying Overripening and Reducing Susceptibility to Gray Mold, Current Biology, 23: 1094-1100. DOI: 10.1016/j.cub.2013.04.072

Jackman R., Yada R., Tung M. (1987): A review: Separation and chemical properties of anthocyanins used for their qualitative and quantitative analysis, Journal of Food Biochemistry, 11: 279-308. https://doi.org/10.1111/j.17454514.1987.tb00128.x

Ahmadiani N., Robbins R.J., Collins T.M., Giusti M.M. (2014): Anthocyanins contents, profiles, and color characteristics of red cabbage extracts from different cultivars and maturity stages. Journal of Agricultural and Food Chemistry, 62 : 7524-7531. https://doi.org/10.1021/jf501991q

Martín, J., Navas, M. J., Jiménez-Moreno, A. M., Asuero, A. G. (2017): Anthocyanin Pigments: Importance, Sample Preparation and Extraction, Chapter 5, DOI: 10.5772/66892

Huang D, Ou B, Hampsch-Woodill M, Flanagan JA, Prior RL. (2002) Highthroughput assay of oxygen radical absorbance capacity (ORAC) using a multichannel liquid handling system coupled with a microplate fluorescence reader in 96-well format, Journal of Agricultural and Food Chemistry, 50: 4437 4444. DOI: $10.1021 / \mathrm{jf0} 201529$

Pojer E., Mattivi F., Johnson D., Stockley C.(2013) The case for anthocyanin consumption to promote human health: Review, Comprehensive Reviews in Food Science and Food Safety, 12, 438-507. https://doi.org/10.1111/1541-4337.12024

Bueno M., Plaza P., Escudero F., Jiménez A., Fett R., Asuero A. (2012): Analysis and antioxidant capacity of anthocyanin pigments. Part II: Chemical structure, color, and intake of anthocyanins, Critical Reviews in Analytical Chemistry, 42 126-151. https://doi.org/10.1080/10408347.2011.632314 